\title{
Localization with multicomponent seismic array
}

\author{
L.A. Inza*†§, J.I. Mars*, J.P. Métaxian ${ }^{\dagger}$, G.S. O’Brien ${ }^{\ddagger}$ and O. Macedo ${ }^{\S}$ \\ ${ }^{*}$ GIPSA-Lab,Dept Image and Signal, Grenoble Institute of Technology, BP 46, 38402 Saint Martin dHères, France \\ ${ }^{\dagger}$ Institut des Sciences de la Terre IRD R219 CNRS, Le Bourget du Lac, France \\ ${ }^{\ddagger}$ School of Geological Sciences, University College Dublin, Ireland \\ $\S$ Instituto Geofisico del Peru, Lima, Peru \\ Email: jerome.mars@gipsa-lab.grenoble-inp.fr, Phone: (33) 476.826.253
}

\begin{abstract}
Seismo-volcano source localization is essential to improve our understanding of volcano systems. The lack of clear seismic wave phases prohibits the use of classical location methods. Seismic antennas composed of one-component (1C) seismometers provide a good estimate of the back-azimuth of the waveeld. The depth estimation, on the other hand, is difcult or impossible to determine. In order to determine the source location parameters (back-azimuth and depth), we extend the $1 \mathrm{C}$ seismic antenna approach to $3 \mathrm{Cs}$. This communication discusses a highresolution location method using a $3 \mathrm{C}$ array survey (3C-MUSIC algorithm) with data from two seismic antennas installed on an andesitic volcano in Peru (Ubinas volcano). After introducing the 3C MUSIC processing, we evaluate the robustness of the location method on a full waveeld 3D synthetic dataset generated using a digital elevation model of Ubinas volcano and an homogeneous velocity model. Results show that the back-azimuth determined using the 3C array has a smaller error than a $1 \mathrm{C}$ array. Only the 3C method allows the recovery of the source depths. Finally, we applied the 3C-MUSIC to two seismic events recorded in 2009. Therefore, extending $1 \mathrm{C}$ arrays to $3 \mathrm{C}$ arrays in volcano monitoring allows a more accurate determination of the source epicenter and now an estimate for the depth.
\end{abstract}

\section{INTRODUCTION}

Source location in term of back-azimuth and depth determination is a fundamental goal in volcano monitoring. Locating seismic events (LP) is necessary to improve the knowledge of the dynamics and magmatic systems, but it is extremely difficult to do it by classical methods (as phase picking or cross-correlation technique [1]). Here we focus on the multicomponent array method for locating these events. Dense one-component (1C) array methods based on time delays between close sensors, have been used by several authors ( [2], [3] ) and allow a good estimation of the back-azimuth of the wavefield. Unfortunately, the depth estimation is poorly resolved because incidence angle is very difficult to determine. To overcome this problem, triaxial sensors (3C) can be used. In this work we focus on the improvement in back-azimuth resolution and depth determination obtained by $3 \mathrm{C}$ rather than $1 \mathrm{C}$ seismometers. In our study two $3 \mathrm{C}$ arrays of 12 threecomponent broadband seismometers were installed on Ubinas volcano, Peru, in March 2009 in order to determine the backazimuth and depth of the seismo-volcano sources. Ubinas volcano, situated in the Central Volcanic Zone with a caldera floor lying approximately $5100 \mathrm{~m}$ above sea level (Fig. 1a), is considered as the most active Peruvian volcano during the last 500 years, threatening 3,500 people living on the edge of the Ubinas valley. At the time of the experiment, the eruption was characterized by almost permanent ash emissions. Source location of the LP events with a higher resolution compared to the $1 \mathrm{C}$ dense array methods, particularly in the depth determination, is the main objective of this work. To achieve it and before working with real wavefield dataset, we performed several numerical simulations of seismic wave propagation using a 3D digital elevation map and heterogeneous velocity model determined from a tomography study [4]. Sources were placed at 8 different depths below the crater and receivers are situated at the same positions as the two field experimental cross-shaped arrays (Fig. 1b). New 3C-MUSIC and 1C-Music [5] are applied to the synthetic data to determine the backazimuth, the incidence angle and the depth for both arrays and all sources. This procedure is after applied to the real data recorded in March 2009.

\section{PROCESSING APPROACH}

We consider $P$ sources travelling from different directions, and impinging at the antenna of $N$ triaxial sensors $(P<N)$. Let $w_{n}(t)$, the signal recorded by one component of the the $n^{\text {th }}$ sensor in the time-space domain as.

$$
w_{n}(t)=\sum_{p=1}^{P} s_{p}\left(t-\tau_{n, p}\right)+b_{n}(t) ; \quad n=0,1, \ldots, N-1
$$

where, $s_{p}(t)$ is the $p^{t h}$ source signal, $\tau_{n, p}$ is the relative propagation time delay of the $p^{t h}$ source for the $n^{t h}$ sensor. The noise $b_{n}(t)$ is usually assumed to be Gaussian, uncorrelated with the sources and both temporally and spatially white with variance $\sigma_{B}^{2}$. The corresponding relative propagation time delay is defined as $\tau_{n, p}=\mathbf{d}_{\mathbf{n}} \cdot \mathbf{u}\left(\theta_{p}, \phi_{p}\right)$. where, $\mathbf{d}_{n}$ is the relative position vector of sensor " $n$ " with respect to the first sensor located at $(0,0,0)$ and $\mathbf{u}\left(\theta_{p}, \phi_{p}\right)$ is the slowness vector indicating the direction of the $p^{t h}$ source. The antenna output of the equation (1) for narrowband signals can be represented in matrix form as:

$$
\mathbf{W}\left(\mathbf{f}_{\mathbf{o}}\right)=\mathbf{A}\left(\mathbf{f}_{\mathbf{o}}\right) \mathbf{S}\left(\mathbf{f}_{\mathbf{o}}\right)+\mathbf{B}\left(\mathbf{f}_{\mathbf{o}}\right)
$$

where, the $N \times P$ matrix $\mathbf{A}\left(\mathbf{f}_{\mathbf{o}}\right)$ is the "array response matrix" or "steering matrix" [6] and is given in equations (3). The $P$ sources are represented by a $P \times 1$ matrix as $\mathbf{S}\left(\mathbf{f}_{\mathbf{o}}\right)=$ $\left[S_{1}\left(f_{o}\right), \ldots, S_{P}\left(f_{o}\right)\right]^{T}$.

$$
\mathbf{A}\left(\mathbf{f}_{\mathbf{o}}\right)=\left[\mathrm{a}\left(\theta_{1}, \phi_{1}\right), \mathrm{a}\left(\theta_{2}, \phi_{2}\right), \ldots, \mathrm{a}\left(\theta_{P}, \phi_{P}\right)\right]
$$



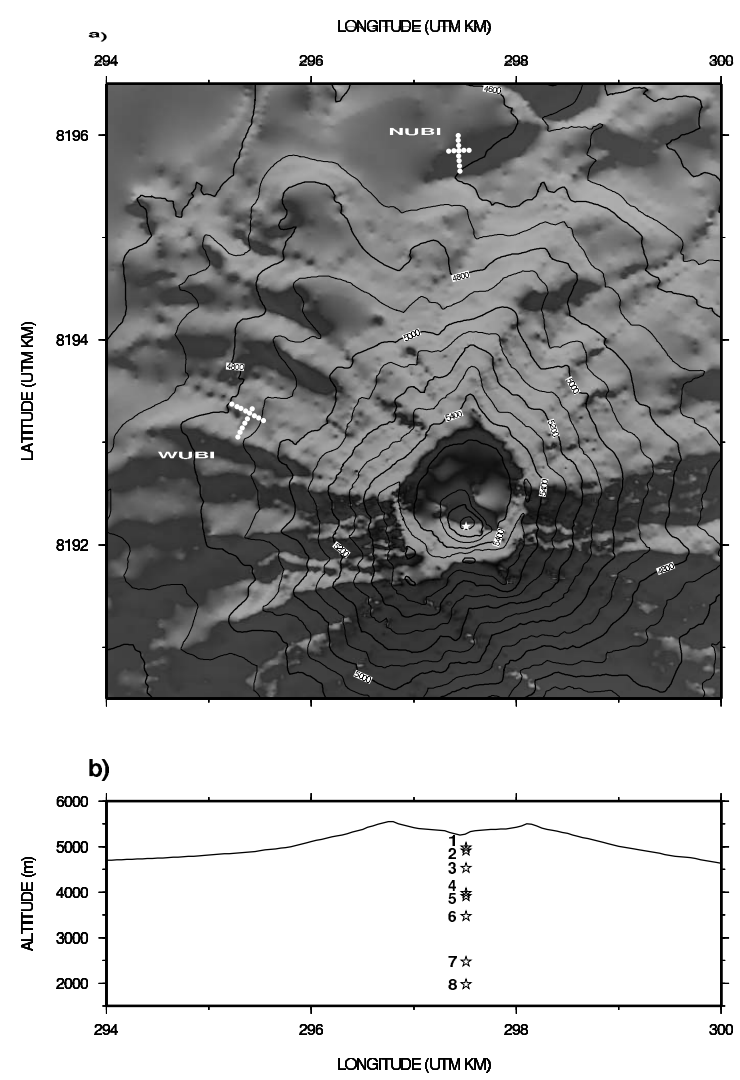

Fig. 1. a) Map of Ubinas volcano showing the location of the north (NUBI) and the north-west (WUBI) antennas, b) East-West profile through the crater showing altitude and depths of the synthetic sources for the 3D synthetic dataset.

$$
\mathrm{a}_{p}\left(\theta_{p}, \phi_{p}\right)=\frac{1}{\sqrt{N}}\left[\begin{array}{llll}
1 & e^{-2 \pi j\left(\mathbf{d}_{2} \cdot \mathbf{k}_{p}\right)} \ldots . & e^{-2 \pi j\left(\mathbf{d}_{N} \cdot \mathbf{k}_{p}\right)}
\end{array}\right]^{T}
$$

with $\mathbf{k}_{p}$ the wavenumber vector. Usually, $\mathbf{A}\left(\mathbf{f}_{\mathbf{o}}\right)$ is a full rank matrix assuming that the array manifolds $\mathrm{a}_{p}\left(\theta_{p}, \phi_{p}\right)$ with different path directions are independent. MUltiple SIgnal Classification (MUSIC) [5] is an eigen structure subspace analysis method, that is widely used in geophysics, particularly to enhance the signal-to-noise ratio in order to estimate the direction of arrival of multiple waves impinging the array [7], [8]. To extend 1C-MUSIC to 3C, a data window for all components of $3 \mathrm{C}$ sensors array is selected, corresponding to the first arrival signal of LP event. The data model for every bin sampled is given as:

$$
\mathbf{W}_{m}=\left[\begin{array}{lll}
\mathbf{X} \mathbf{n}_{m} & \mathbf{Y} \mathbf{n}_{m} & \mathbf{Z} \mathbf{n}_{m}
\end{array}\right]
$$

where, $X n, Y n$ and $Z n$ represent the data vector of each component of the sensor for the sample $m$. Then the crossspectral correlation estimation over $M$ frequencies bins is defined as:

$$
\widehat{\boldsymbol{\Gamma}}_{W}=\sum_{m=1}^{M} \xi\left\{\mathbf{W}_{m} \mathbf{W}_{m}^{\mathbf{H}}\right\}
$$

$\xi$ denote the mathematical expectation operator and $\mathbf{H}$ is the conjugate transpose. The cross-spectral matrix $\widehat{\boldsymbol{\Gamma}}_{W}$ can be writen as [7], [9], [10].

$$
\begin{gathered}
\widehat{\boldsymbol{\Gamma}}_{W}=\boldsymbol{A} \xi\left\{\mathbf{S} \mathbf{S}^{H}\right\} \boldsymbol{A}^{H}+\xi\left\{\mathbf{B} \mathbf{B}^{H}\right\} \\
\widehat{\boldsymbol{\Gamma}}_{W}\left(f_{o}\right)=\boldsymbol{A}\left(f_{o}\right) \widehat{\boldsymbol{\Gamma}}_{s}\left(f_{o}\right) \boldsymbol{A}^{H}\left(f_{o}\right)+\sigma_{B}^{2}\left(f_{o}\right) \mathbf{I}
\end{gathered}
$$

where, $\widehat{\boldsymbol{\Gamma}}_{s}\left(f_{o}\right)=\xi\left\{\mathbf{S} \mathbf{S}^{H}\right\}$ is the cross-spectral matrix of the source, $\mathbf{I}$ is the identity matrix and $\sigma_{B}^{2}$ is the variance of the noise. The eigenstructure of $N \times N$ cross-correlation matrix $\widehat{\boldsymbol{\Gamma}}_{W}$ solves the eigenvalues $\lambda_{n}$ and eigenvectors $\mathbf{v}_{\mathbf{n}}$ respectively ( $\mathrm{N}=$ number of sensors). The $P$ largest eigenvalues correspond to the signal subspace, while $N-P$ eigenvalues correspond to the noise subspace. The 3C-MUSIC estimator is given in the equation (7) by $M_{3 C}$ which computes the azimuth and incidence angles.

$$
M_{3 C}(\theta, \phi)=\frac{1}{\mathbf{A}^{H}(\theta, \phi) \boldsymbol{\Pi}^{\perp} \mathbf{A}(\theta, \phi)}
$$

where, $\boldsymbol{\Pi}^{\perp}=\sum_{n=p+1}^{N} \mathbf{v}_{n} \mathbf{v}_{n}^{H}$ is the noise sub-space projector.

\section{APPLICATION: SYNTHETIC AND REAL DATASET}

We deployed on Ubinas volcano between May and July 2009, two cross-shaped antennas (NUBI and WUBI) with 12 3C seismometers each (Fig. 1a.). Continuous recordings were acquired with a sampling frequency of $100 \mathrm{~Hz}$. Distances between seismometers was set to approximately 50 meters. Seventeen explosion earthquakes and 450 of LP events were recorded during the experiment.

\section{A. Synthetic Data Analysis}

In order to test the accuracy of the location methods, a 3D discrete numerical elastic lattice method [11] coupled with a digital elevation map of Ubinas topography and the 2009 experimental array locations, was used to create a full waveform synthetic dataset. In order to compare the $3 \mathrm{C}$ and $1 \mathrm{C}$ methods, we analysed the full synthetic dataset for the $3 \mathrm{C}$ and only the vertical components for the 1C. Same analysis for both arrays and for all eight sources are done. The crossspectral matrix was then calculated by using 32 windows around the dominant peak frequency. Comparison between $1 \mathrm{C}$ and $3 \mathrm{C}-$ MUSIC are shown in the Fig. $2 \mathrm{a}$ and $2 \mathrm{~b}$ for NUBI and WUBI antennas respectively. The back-azimuths from the $3 \mathrm{C}$ MUSIC correspond to the model values for both antennas with a resolution of $\pm 3^{\circ}$. 1C-MUSIC gives equivalent results, but with higher errors $\left( \pm 6^{\circ}\right)$. The incident angle varies with depth when it is well determined with the 3C-MUSIC. Knowing the distance from the centre of the antennas and the hypocentre of the sources, depth resolution can be deduced for each antenna (500 $\mathrm{m}$ for NUBI and $400 \mathrm{~m}$ for WUBI). On the other hand, the 1C-MUSIC analysis does not allow the depth to be determined. The theoretical velocity has an accuracy of \pm 150 $\mathrm{m} / \mathrm{s}$ using the $3 \mathrm{C}$-MUSIC algorithm. The $1 \mathrm{C}$-MUSIC measures higher velocities at NUBI and lower velocities at WUBI. For NUBI antenna, the 1C-MUSIC analysis gives depths close to the model values for the superficial sources (1,2 and 3) while depths for sources 4, 5, 6, 7 and 8 are far away from the model 
values. None of incident angle of sources can be distinguished with the 1C-MUSIC analysis. For WUBI antenna, the $1 \mathrm{C}$ MUSIC analysis gives higher incident angles than the model values. Errors are larger than the $3 \mathrm{C}$ algorithm. The $1 \mathrm{C}$ MUSIC analysis does not give reliable solutions for any of the synthetic source depths. In summary, incident angles obtained by the 3C-MUSIC algorithm are close to the theoretical values for both antennas, whereas those obtained with the 1C-MUSIC are not reliable. In order to represent the results for the depth
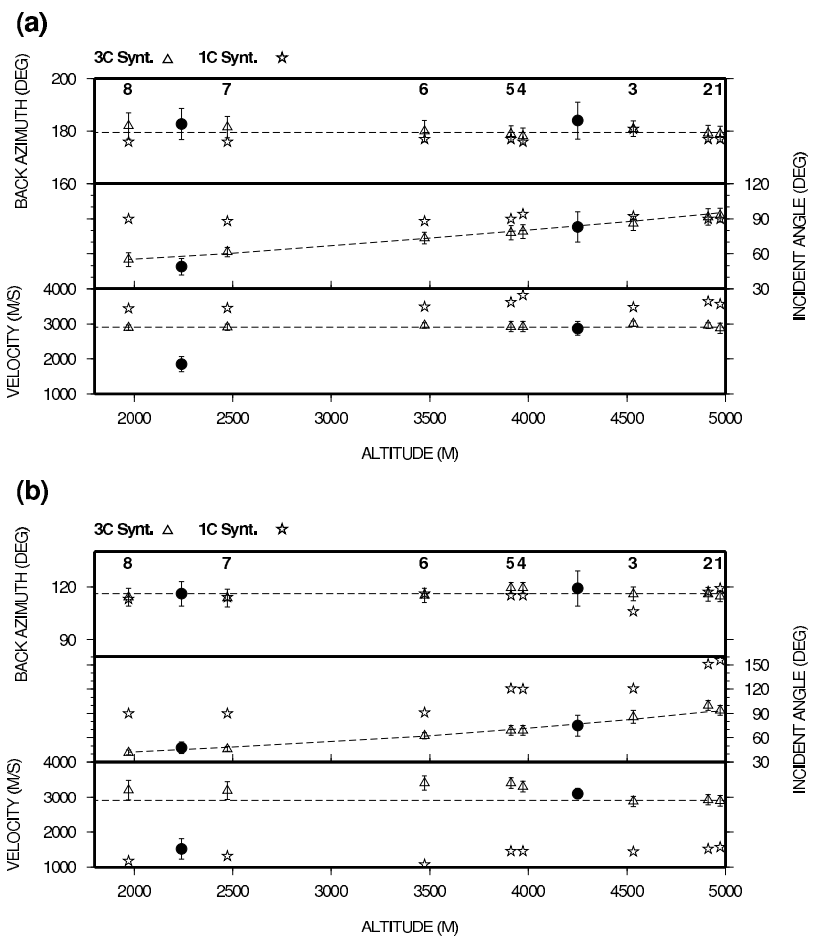

Fig. 2. Results obtained for the synthetic data calculated for the eight sources. Open triangles and open stars represent results obtained with the 3C-MUSIC and 1C-MUSIC, respectively. Sources are numbered as in figure 1b. a) Backazimuth, incidence angle and apparent velocity for NUBI antenna. b) Backazimuth, incidence angle and apparent velocity for WUBI antenna. Dash lines represent the values. The filled circles represent the real data results

of sources, the PDF of the source position is derived from the different PDF's of the back-azimuth and the incident angle [3]. Hence, 3C-MUSIC allows to locate the synthetic sources in depth and in all the cases. 1C analysis can not give this results. Figure 3 shows in details the results obtained for each synthetic source with the 2 antennas NUBI and WUBI (Fig 3 left) and with a third synthetic antenna added and laying at Est part (Fig 3 right). The horizontal position is well determined for all sources. Looking at the vertical views and comparing with exact position given in Fig $1 \mathrm{~b}$, the estimated source position is well for the 2 highest sources which are very close together (first and second subplots). Uncertainty is larger for the source 3 in case of 2 antennas but position is better estimated in case of 3 antennas. The PDF of the source position gives a good solution for sources 4 and 5 . These sources 4 and 5 can be clearly differentiated from sources 1,2 and 3 . It is difficult to differentiate sources 7 and 8 in 2 antennas, but adding a third antenna allows to separate them.
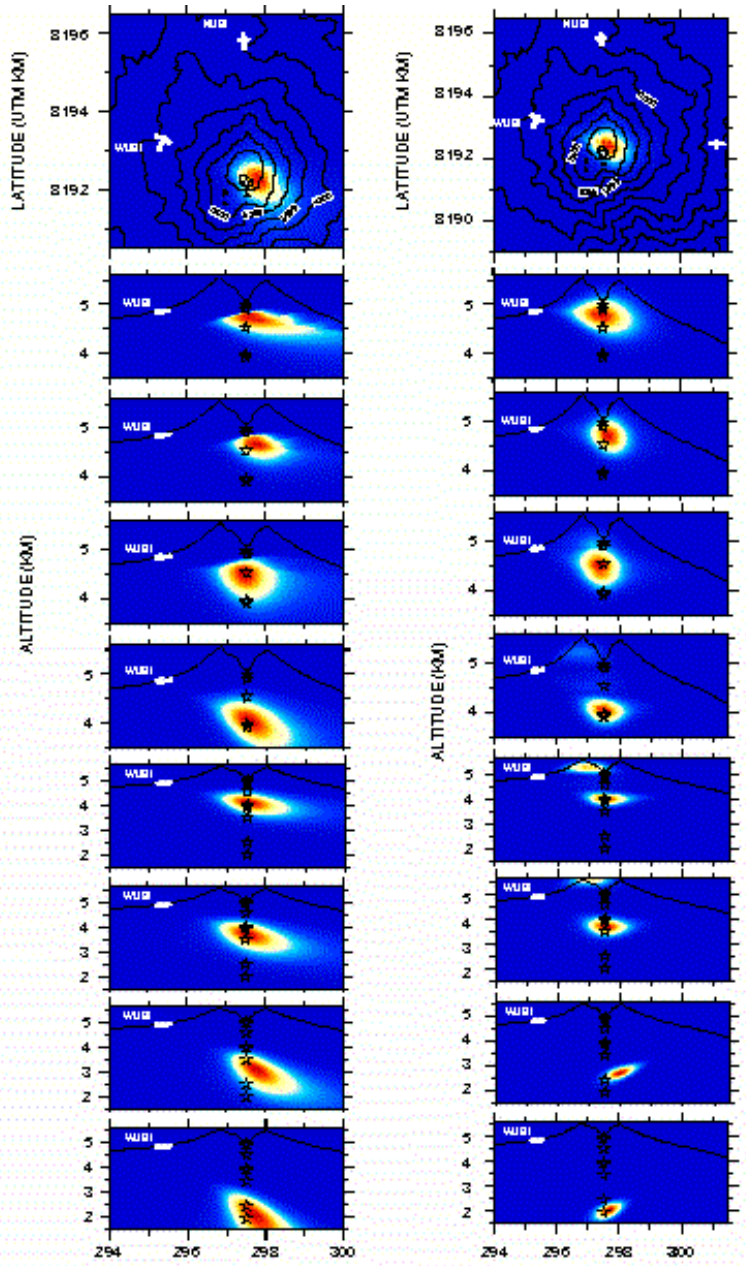

Fig. 3. 8 Synthetic sources localizations with: 2 antennas NUBI and WUBI (left part) and 3 antennas (right part). Exact position is given by stars point related to fig $1 b$.

1) Real Data Analysis: We discuss the performance of $3 \mathrm{C}$ MUSIC method on 2 real seismic events recorded at Ubinas volcano recorded on the 2 antennas (an explosion earthquake signal and an LP event). Fig. $4 \mathrm{~b}$ and $\mathrm{c}$ gives all information in time and frequency at NUBI antenna. Results of the source position for the LP event and the explosion earthquake are showed in Fig. 5. source PDF for the LP event is situated $3000 \mathrm{~m}$ below the bottom of the crater at the altitude of 2240 $\mathrm{m}$ with a radius of $730 \mathrm{~m}$. The source area of the explosion is situated $150 \mathrm{~m}$ West and $1000 \mathrm{~m}$ below the bottom of the crater at an altitude of $4200 \mathrm{~m}$, the radius $\mathrm{R}$ is $660 \mathrm{~m}$.

\section{CONCLUSION}

We have presented a source localization method (3CMUSIC) based on the use of $3 \mathrm{C}$ arrays and, compared it with 1C-MUSIC. All results in terms of back-azimuth, incident angles, velocities and depth is estimated with higher precision with 3C-MUSIC than 1C MUSIC in synthetic case. In a real 

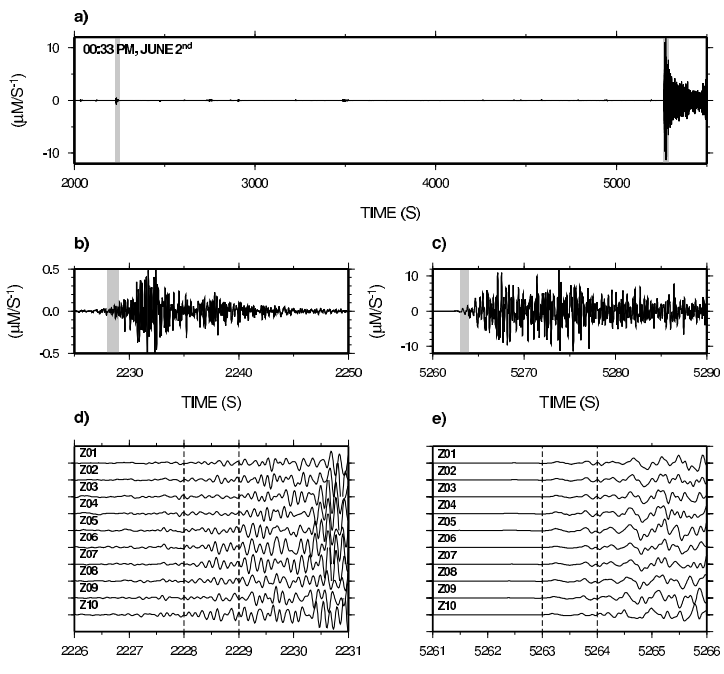

f) g)
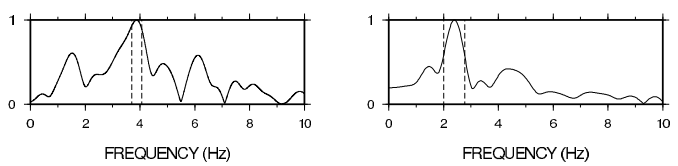

Fig. 4. a) Z component seismogram of the LP event and explosion earthquake recorded by the central station of NUBI antenna. The time and date of the first sample is indicated in the upper left of the record. Shaded zones represent part of the signals enlarged in b) and c). d) and e) $\mathrm{Z}$ component of the LP event and the explosion earthquake recorded by 10 stations of NUBI antenna. The vertical dash lines in d) and e) indicate the time window selected for the processing. f) and g) Averaged energy spectrum calculated for all the receivers and all the components, where the vertical dash lines represent the frequency windows used for the cross spectral matrix calculation

experiment, we located a depth of the LP event and an explosion earthquake using the 3C-MUSIC. We conclude that 3CMUSIC provides realistic estimates of the depth of volcanic sources, unlike the 1C-MUSIC or other antenna methods based on time delays measurements. Given the performance of the 3C-MUSIC algorithm, we will apply it to other explosions and LP events recorded at Ubinas during the experiment to better characterize the eruptive dynamics of this volcano. Further studies must take into account the bandwidth of the signal with wideband 3C MUSIC or Quaternion MUSIC processing [12].

\section{REFERENCES}

[1] L. De Barros, C. J. Bean, I. Lokmer, G. Saccoroti, L. Zuccarello, G. S. O'Brien, and J.-P. Métaxian, "Source geometry from exceptionally high resolution long period event observations at $\mathrm{mt}$ etna during the 2008 eruption," Geophys Researh Letters, vol. 36 L24-305, p. 5, 2009.

[2] M. La Rocca, G. Saccorotti, E. Del Pezzo, and J. Ibáñez, "Probabilistic source location of explosion quakes at stromboli volcano estimated with double array data," Journal of Volcanology and Geothermal Research, vol. 131, pp. 123-142, 2004.

[3] J.-P. Métaxian, P. Lesage, and B. Valette, "Locating sources of volcanic tremor and emergent events by seismic triangulation," Geophys Researh Letters, vol. 107(B10), p. 2243 (18PP), 2002.

[4] V. Monteiller, J.-L. Got, J. Virieux, and P. Okubo, “An efficient algorithm for double-difference tomography and location in heterogeneous media, with an application to the kilauea volcano.," Journal of Geophysical Research, vol. 110, p. B12306 (22PP), 2005.

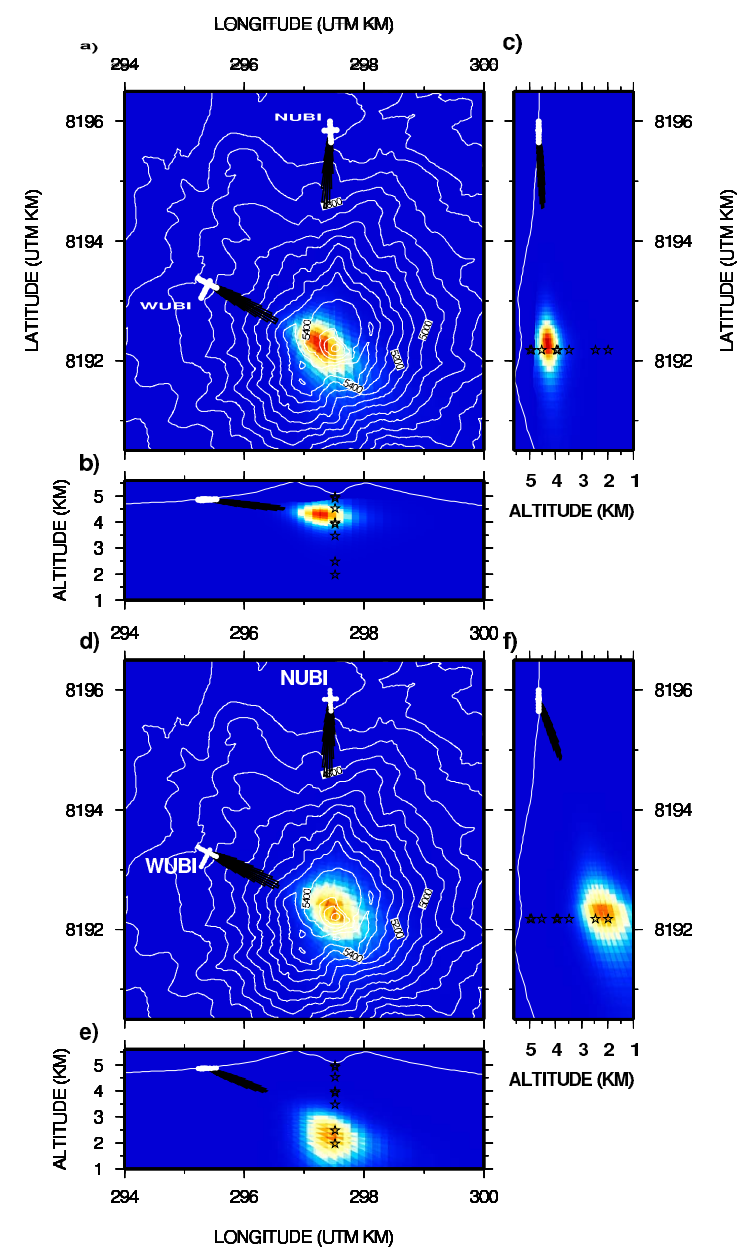

Fig. 5. PDF of the source position for the explosion earthquake (a-c) and the LP event (d-f). a) horizontal view at $4200 \mathrm{~m}$ depth, b) vertical view oriented WE, c) same as b) oriented NS. d) horizontal view at $2240 \mathrm{~m}$ depth, e) vertical view oriented WE. f) same as e) oriented NS. The PDFs are represented as rose diagrams with an increment of $5^{\circ}$

[5] R. O. Schmidt, "Multiple emitter location and signal parameter estimation," IEEE Transactions Antennas and Propagation, vol. 34(3), pp. 276-280, 1986.

[6] S. Miron, N. Le Bihan, and J. I. Mars, "High resolution vector-sensor array processing based on biquaternions," IEEE Transactions on Signal Processing, vol. 54, pp. 1218-1229, 2006.

[7] C. Paulus and J. I. Mars, "Vector-sensor array processing for polarization parameters and doa estimation," EURASIP Journal on Advances in Signal Processing, vol. 2010, p. Article ID 850265 (13PP), 2010.

[8] K. T. Wong and M. D. Zoltowski, "Self-initiating music direction finding \& polarization estimation in spatio-polarizational beamspace," IEEE Transactions on Antennas and Propagation, vol. 48, pp. 671-681, 2000.

[9] C. Paulus, J. I. Mars, and P. Gounon, "Wideband spectral matrix filtering for multicomponent sensors array," Signal Processing, vol. 85, pp. 1723$1743,2005$.

[10] S. Miron, N. Le Bihan, and J. I. Mars, "Vector-sensor music for polarized seismic sources localization," EURASIP Journal on Applied Signal Processing, vol. 2005, pp. 74-84, 2005.

[11] G. S. O'Brien and C. J. Bean, "A 3d discrete numerical elastic lattice method for seismic wave propagation in heterogeneous media with topography," Geophysical Research Letters, vol. 31, pp. L14608.1L14608.4, 2004.

[12] M. Hobiger, C. Cornou, P. Bard, and N. Le Bihan, "Musique: A quaternion-based array processing technique for surface wave polarization analysis," IEEE Conf. Statistical Signal Processing Workshop, Nice, vol. 28-30 June, 2011. 